\title{
Chemistry and pharmacology of saponins: special focus on cytotoxic properties
}

\author{
This article was published in the following Dove Press journal: \\ Botanics:Targets and Therapy \\ 7 October 2011 \\ Number of times this article has been viewed
}

\author{
Mayank Thakur' \\ Matthias F Melzig² \\ Hendrik Fuchs' \\ Alexander Weng' \\ 'Institute of Laboratory \\ Medicine, Clinical Chemistry \\ and Pathobiochemistry, Charité - \\ Universitätsmedizin Berlin, Berlin; \\ ${ }^{2}$ Institute of Pharmacy, Free University \\ of Berlin, Berlin, Germany
}

Correspondence: Alexander Weng Institut für Laboratoriumsmedizin,

Klinische Chemie und Pathobiochemie,

Charité Universitätsmedizin

Berlin, Campus Benjamin Franklin,

Hindenburgdamm 30, D-I2200 Berlin,

Germany

Tel +49308445 3097

Fax +49 3084454152

Email alexander.weng@charite.de

\begin{abstract}
Saponins are bioactive compounds produced mainly by plants but also by some marine organisms and insects. In the recent past, there has been unforeseen interest in the clinical utilization of saponins as chemotherapeutic agents. The research on saponins in various forms as a treatment for cancer has generated a lot of potential. The advent of nanotechnology and the cytotoxicity enhancing properties of saponins are some of the highlights of the current decade. This review gives an updated overview of the clinical potential that saponins hold as cytotoxic agents, and covers the literature for 1957-2011, with the main focus on research conducted in the last decade. It is conceivable that saponins hold a lot of therapeutic potential and could be a lead for identification of synthetic or semisynthetic molecules for the treatment of cancer via membrane-mediated or transport-mediated pathways.
\end{abstract}

Keywords: triterpenoids, clinical use, saponin nanoparticles, synergistic enhancement, toxins

\section{Introduction}

Saponins are bioactive compounds produced mainly by plants, but also by some marine organisms and insects. Chemically, they generally occur as glycosides of steroids or polycyclic triterpenes. ${ }^{1}$ Because of their lyobipolar properties, they are able to interact with cell membranes and are also able to decrease the surface tension of an aqueous solution. This activity is the reason for the name "saponin", derived from the Latin word "sapo", which refers to the formation of a stable soap-like foam in aqueous solution. ${ }^{2}$

According to the chemical character of the aglycone (known as sapogenin), the saponins are divided into steroidal and triterpenoid saponins. Some authors also count the glycosides of steroidal alkaloids and cucurbitacines in the chemical classification of saponins. Steroidal saponins from plants are mainly compounds containing 27 carbon atoms forming the core structures, ie, spirostan (16 $\beta$, 22:22 $\alpha$, 26-diepoxy-cholestan, Figure 1 and Table 1) and furostan (16 $\beta, 22$-epoxycholestan). ${ }^{3}$ In nature, the saponins mainly consist of (25S)-spirostan derivatives ("real" saponins, or neosaponins), (25R)-spirostan derivatives ("isosaponins"), and $(25 S)$ - and (25R)-furostan derivatives. There are rare reports of aglycone derivatives from furostan [spirofuran, $(22 R)-16 \beta, 22: 22,25$-diepoxy-cholestan] and pyrostan [(22R)-22, 26-epoxy-cholestan], as well as derivatives of cholestan without a fused O-heterocycle, eg, cholestan-23-on-derivatives or pregnan derivatives. The ring systems $\mathrm{A} / \mathrm{B} / \mathrm{C} / \mathrm{D}$ are linked together in the order trans-trans-trans ( $5 \alpha$ derivatives) or cis/trans/trans (5 $\beta$ derivatives). ${ }^{4}$ Table 1 shows the most commonly occurring structures 


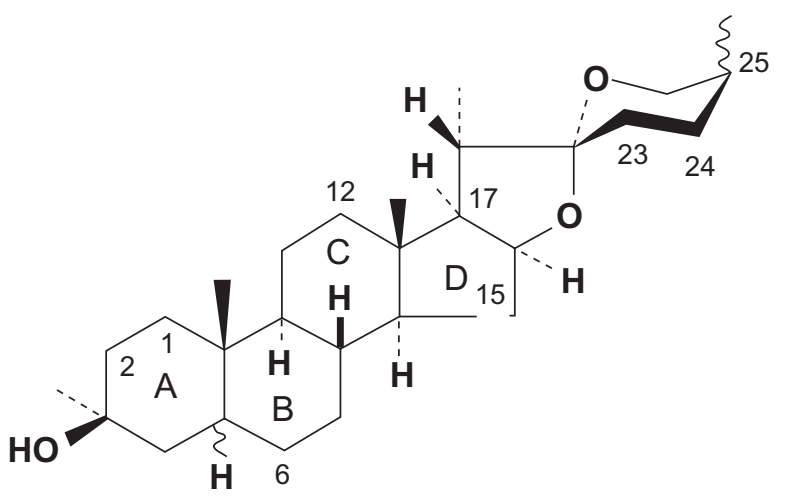

Figure I Core structure of spirostan.

of aglycones from steroidal saponins. Triterpenoidal saponins mainly contain aglycones with 30 carbon atoms or their norderivatives. The most commonly occurring core structures are pentacyclic oleanans (Figure 2 and Table 2) and tetracyclic dammarans. Other aglycones of triterpenoid saponins are ursan, lupan, and hopan. The ring systems A/B/C/D/E for oleanan and ursan derivatives are linked together in the order trans-trans-trans-trans, for lupan derivatives in the order trans-trans-trans-cis, and for the rings $\mathrm{A} / \mathrm{B} / \mathrm{C} / \mathrm{D}$ in dammaran derivatives in the order trans-trans-trans.

The broad spectrum of saponins is mainly a result of the varying degree of hydroxylation on the aglycone. The pattern of substituents on the frequently occurring aglycones derived from the oleanane structure of saponins is detailed in Table 2. The hydroxyl group at position C-3 is found in all structures; very often hydroxyl groups are also reported at positions $\mathrm{C}-16, \mathrm{C}-21$, and C-22, and less often in positions $\mathrm{C}-2$ and $\mathrm{C}-15$. The methyl groups in positions C-23, C-24, C-28, C-29, and C-30 can be oxidized to $\mathrm{CH}_{2} \mathrm{OH}-$ or $\mathrm{COOH}-$ moieties, and in some cases also to a $\mathrm{CHO}-$ group. This is an especially interesting structural element in saponins, with specific effects on pharmacological activity, as reported later in this review. Also reported are the presence of epoxy groups, keto functions, and double bonds between C-12 and C-13. The hydroxyl groups can be acylated, and this leads to the formation of ester saponins. Acidic components in such cases are very often formic, acetic, $n$ - and iso-butyric, isovalerianic, $\alpha$-methyl butyric, angelic, tiglic, benzoic, cinnamic, and ferulic acid, and, in some cases, sulfuric acid. ${ }^{5-7}$

The monosaccharide moieties of saponins include a broad spectrum of simple sugars, like D-glucose, D-galactose, D-fructose, 3-methyl-D-glucose, D-xylose, L-arabinose, L-rhamnose, L-fucose, D-apiose, and D-chinovose, in addition to D-glucuronic acid and D-galacturonic acid. The sugars often bind in position C-3 via the hydroxyl group as glycosides, or as esters bound via the carboxylic moiety in position $\mathrm{C}-28$.

The best known saponins are secondary metabolites produced in Magnoliophyta, covering both dicotyledons and monocotyledons. However, the majority of saponinproducing species has been found within dicotyledons. ${ }^{3}$ Steroidal saponins are produced especially in some families of the monocotyledons, eg, Agavaceae, Alliaceae, Asparagaceae, Convallariaceae, Dioscoreaceae, Liliaceae, Trilliaceae, and Smilacaceae. In dicotyledons, steroidal saponins are detected only in a few families, eg, Fabaceae, Solanaceae, and Scrophulariaceae. ${ }^{8}$ The starting point for the biosynthesis of steroidal saponins is cholesterol, presumably by hydroxylation at position C-26 or C-27, and the linkage of the resulting hydroxyl group with glucose. After that, hydroxylation reactions occur at positions C-16 and C-22, followed by dehydrogenation and formation of the fused furan ring. In some cases, the biosynthesis starts also from cycloartenol which is then transformed to cholesterol..$^{9,10}$

Table I Structural features of different spirostan derivatives for saponins and their configurations

\begin{tabular}{|c|c|c|c|c|c|c|c|c|}
\hline \multirow[t]{3}{*}{ Type of sapogenin } & \multicolumn{8}{|c|}{ Substituent at different C-positions } \\
\hline & \multirow[t]{2}{*}{$I \beta$} & \multirow[t]{2}{*}{$2 \alpha$} & \multirow[t]{2}{*}{$15 \beta$} & \multirow[t]{2}{*}{25} & \multirow[t]{2}{*}{ Others } & \multirow[t]{2}{*}{ Double bonds } & \multicolumn{2}{|c|}{ Configuration at } \\
\hline & & & & & & & C-5 & C-25 \\
\hline Digitogenin & & $\mathrm{OH}$ & $\mathrm{OH}$ & $\mathrm{CH}_{3}$ & & & $\alpha$ & $R$ \\
\hline Diosgenin & & & & $\mathrm{CH}_{3}$ & & $\Delta^{5}$ & - & $R$ \\
\hline Gitogenin & & $\mathrm{OH}$ & & $\mathrm{CH}_{3}$ & & & $\alpha$ & $R$ \\
\hline Hecogenin & & & & $\mathrm{CH}_{3}$ & $12=0$ & & $\alpha$ & $R$ \\
\hline Neoruscogenin & $\mathrm{OH}$ & & & $=\mathrm{CH}_{2}$ & & $\Delta^{5}$ & - & - \\
\hline Pennogenin & & & & $\mathrm{CH}_{3}$ & $\mathrm{I} 7 \alpha \mathrm{OH}$ & $\Delta^{5}$ & & $R$ \\
\hline Sarsapogenin & & & & $\mathrm{CH}_{3}$ & & & $\beta$ & $S$ \\
\hline Smilagenin & & & & $\mathrm{CH}_{3}$ & & & $\beta$ & $R$ \\
\hline Tigogenin & & & & $\mathrm{CH}_{3}$ & & & $\alpha$ & $R$ \\
\hline Yamogenin & & & & $\mathrm{CH}_{3}$ & & $\Delta^{5}$ & - & $S$ \\
\hline
\end{tabular}




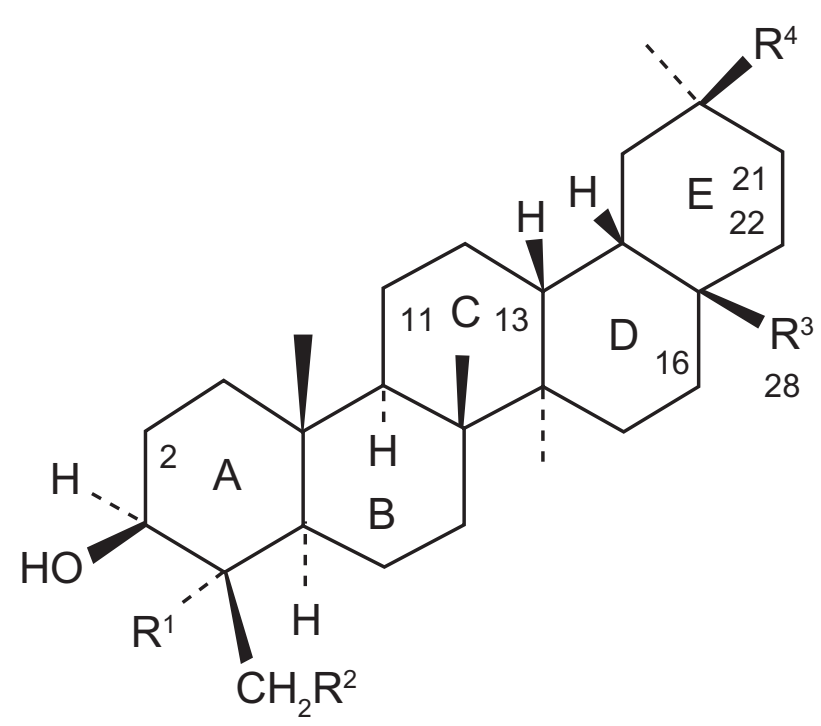

Figure 2 Core structure of triterpenoid sapogenins with arrangement of rings ABCDE.

Triterpenoid saponins are mainly found in dicotyledons. Approximately 60 families of this taxon produce this type of saponin, including Apiaceae, Araliaceae, Caryophyllaceae, Chenopodiaceae, Fabaceae, Hippocastanceae, Primulaceae, Ranunculaceae, Sapotaceae, and Theaceae. No saponins have been detected so far in Gymnospermae, Coniferophytina, and Cycadophytina. ${ }^{11}$

Part of the biogenesis of triterpenoid saponins is cyclization of the squalene to dammarans, which are modified by ring openings and/or followed by ring closure via lupans and oleanans to ursans. ${ }^{4}$ Terpenoid biosynthesis in plants is strictly compartmentalized and based on the mevalonate pathway. ${ }^{12}$ In order to interact with biological membranes, acidic saponins must be bound to at least three monosaccharide moieties, and neutral saponins to at least two sugar molecules. ${ }^{13}$ In contrast with cardiac glycosides, most saponins contain branched chains of oligosaccharides, often terminated by pentoses. According to the number of directly bound sugar chains at the aglycone, the saponins are categorized into monodesmosides (one chain), bisdesmosides (two chains), or trisdesmosides (three chains). Further to the structural attributes and chemical classification mentioned above, saponins have been ascribed numerous pharmacological functions. Preclinical and clinical evaluations of saponins with their pertinent role as cytotoxic agents are discussed in this review.

\section{Pharmacological studies}

Saponins have been ascribed a number of pharmacological actions, ${ }^{1,14-16}$ the important ones being permeabilizing of the cell membrane, ${ }^{4}$ lowering of serum cholesterol levels, ${ }^{17}$ stimulation of luteinizing hormone release leading to abortifacient properties, ${ }^{17}$ immunomodulatory potential via cytokine interplay, ${ }^{14}$ cytostatic and cytotoxic effects on malignant tumor cells, ${ }^{18}$ adjuvant properties for vaccines as immunostimulatory complexes, ${ }^{19}$ and synergistic enhancement of the toxicity of immunotoxins. ${ }^{20,21}$

A number of other activities have been attributed to saponins, and the literature is replete with various pharmacological properties ascribed to the saponins in general.

Table 2 Types of aglycones based on the substitution at different Carbon positions in case of triterpenoidal saponins

\begin{tabular}{|c|c|c|c|c|c|c|c|c|c|c|c|c|c|}
\hline \multirow[t]{2}{*}{ Type of sapogenin } & \multicolumn{13}{|c|}{ Substitution at different Carbon positions } \\
\hline & $2 \beta$ & $3 \beta$ & II & $13 / 28$ & $16 \alpha$ & $21 \beta$ & $22 \alpha$ & $\mathbf{R}^{\prime}$ & $\mathbf{R}^{2}$ & $\mathbf{R}^{3}$ & $\mathbf{R}^{4}$ & $\mathbf{R}^{5}$ & $\Delta^{12}$ \\
\hline \multicolumn{14}{|c|}{ Neutral triterpenoids } \\
\hline Barringtogenol C & & $\mathrm{OH}$ & & & $\mathrm{OH}$ & $\mathrm{OH}$ & $\mathrm{OH}$ & $\mathrm{CH}_{3}$ & $\mathrm{H}$ & $\mathrm{CH}_{2} \mathrm{OH}$ & $\mathrm{CH}_{3}$ & $\mathrm{H}$ & + \\
\hline Priverogenin B & & $\mathrm{OH}$ & & $-O-$ & $\mathrm{OH}$ & & $\mathrm{OH}$ & $\mathrm{CH}_{3}$ & $\mathrm{H}$ & $\mathrm{CH}_{2}^{-}$ & $\mathrm{CH}_{3}$ & $\mathrm{H}$ & - \\
\hline Protoaescigenin & & $\mathrm{OH}$ & & $-0-$ & $\mathrm{OH}$ & $\mathrm{OH}$ & $\mathrm{OH}$ & $\mathrm{CH}_{3}$ & $\mathrm{OH}$ & $\mathrm{CH}_{2} \mathrm{OH}$ & $\mathrm{CH}_{3}$ & $\mathrm{H}$ & + \\
\hline Protoprimulagenin A & & $\mathrm{OH}$ & & & $\mathrm{OH}$ & & & $\mathrm{CH}_{3}$ & $\mathrm{H}$ & $\mathrm{CH}_{2-}^{-}$ & $\mathrm{CH}_{3}$ & $\mathrm{H}$ & - \\
\hline \multicolumn{14}{|c|}{ Triterpenoid monocarbonic acids } \\
\hline Bayogenin & $\mathrm{OH}$ & $\mathrm{OH}$ & & & & & & $\mathrm{CH}_{2} \mathrm{OH}$ & $\mathrm{H}$ & $\mathrm{COOH}$ & $\mathrm{CH}_{3}$ & $\mathrm{H}$ & + \\
\hline Glycyrrhetinic acid & & $\mathrm{OH}$ & $=0$ & & & & & $\mathrm{CH}_{3}$ & $\mathrm{H}$ & $\mathrm{CH}_{3}$ & $\mathrm{COOH}$ & $\mathrm{H}$ & + \\
\hline Gypsogenin & & $\mathrm{OH}$ & & & & & & $\mathrm{CHO}$ & $\mathrm{H}$ & $\mathrm{COOH}$ & $\mathrm{CH}_{3}$ & $\mathrm{H}$ & + \\
\hline Hederagenin & & $\mathrm{OH}$ & & & & & & $\mathrm{CH}_{2} \mathrm{OH}$ & $\mathrm{H}$ & $\mathrm{COOH}$ & $\mathrm{CH}_{3}$ & $\mathrm{H}$ & + \\
\hline Oleanolic acid & & $\mathrm{OH}$ & & & & & & $\mathrm{CH}_{3}$ & $\mathrm{H}$ & $\mathrm{COOH}$ & $\mathrm{CH}_{3}$ & $\mathrm{H}$ & + \\
\hline Polygalic acid & $\mathrm{OH}$ & $\mathrm{OH}$ & & & $\mathrm{OH}$ & & & $\mathrm{CH}_{2} \mathrm{OH}$ & $\mathrm{H}$ & $\mathrm{COOH}$ & $\mathrm{CH}_{3}$ & $\mathrm{H}$ & + \\
\hline Quillajic acid & & $\mathrm{OH}$ & & & $\mathrm{OH}$ & & & $\mathrm{CHO}$ & $\mathrm{H}$ & $\mathrm{COOH}$ & $\mathrm{CH}_{3}$ & $\mathrm{H}$ & + \\
\hline \multicolumn{14}{|c|}{ Triterpenoid dicarbonic acids } \\
\hline Gypsogic acid & & $\mathrm{OH}$ & & & & & & $\mathrm{COOH}$ & $\mathrm{H}$ & $\mathrm{COOH}$ & $\mathrm{CH}_{3}$ & $\mathrm{H}$ & + \\
\hline Medicagenic acid & $\mathrm{OH}$ & $\mathrm{OH}$ & & & & & & $\mathrm{COOH}$ & $\mathrm{H}$ & $\mathrm{COOH}$ & $\mathrm{CH}_{3}$ & $\mathrm{H}$ & + \\
\hline Presenegin & $\mathrm{OH}$ & $\mathrm{OH}$ & & & & & & $\mathrm{COOH}$ & $\mathrm{H}$ & $\mathrm{COOH}$ & $\mathrm{CH}_{3}$ & $\mathrm{OH}$ & + \\
\hline
\end{tabular}


Readers are referred to reviews by Fuchs et $\mathrm{al}^{16}$ and Podolak et $a l,{ }^{22}$ in which the authors discuss the use of saponins as cytotoxic agents. In the following section, we elaborate on the mechanism of action of saponins. This has been detailed in some of the recent publications. ${ }^{15,19,23-28}$ Interestingly, most of the studies carried out so far have been on extracts rich in saponins, with only a few illustrated for isolated triterpenes or steroidal saponins.

Our primary focus is on some isolated plant saponins. In order to delineate and enhance an understanding of their pharmacology, we have also tried to focus more on cell cytotoxicity and in vivo experimental data. Wherever possible, we have focused on clinical studies carried out for the saponins discussed in this paper.

\section{Saponins as cytotoxic agents}

Cytotoxic activity has been described for a number of saponins, and numerous reports of cytotoxic saponins continue to appear in the literature every year. ${ }^{22,29,30}$ One of the first studies on treatment of tumors using saponins was reported in 1960 by Friess et al. ${ }^{31}$ In their study, saponins from the sea cucumber were reported to possess antitumor activity. Following this, more than 400 studies have been reported regarding the saponins and their ability to treat cancer or induce apoptosis. Most of the studies are at the in vitro level, and only $10 \%$ of these were performed at the preclinical level, mostly in rodents. It is worth mentioning that most of the compounds were tested in mice, with only $24 \%$ of studies being done in human cell lines. The major human cell lines studied have been HeLa, MCF-7, MDA-MB43, Caco-2, and Hep-G2 cells, which are representative of cervical, breast, colon, and hepatic carcinomas, respectively.

One of the problems associated with use of saponins as antitumor agents is their high singular toxicity, which is accompanied with a misleading correlation between in vitro and in vivo data, and complicates the possible use of saponins as cytotoxic agents in the clinical setting. There have been sporadic reports on the structure-activity relationship, providing a possible correlation between the cytotoxic effects and certain structural features. Readers are referred to some interesting research by Gauthier et al..$^{24,32,33}$ In a recent study by Liu et al, a synthetic derivative of $\beta$-hederin was evaluated for its cytotoxic properties in five human cell lines (ie, HeLa, MCF-7, HL-60, HT1080, and Hep-G2). ${ }^{34}$ The authors reported synthesis of 13 novel triterpenoid saponins, designed as amide derivatives of the natural cytotoxic saponin, $\beta$-hederin, using a stepwise glycosylation strategy. Most of the evaluated compounds showed effective inhibitory activity against at least one tumor cell line at micromolar concentrations. Based on structure-activity-relationships, the authors concluded that amide substitution at $\mathrm{C}-28$ results in highly cytotoxic derivatives for specific tumor cell lines, and also leads to an increase in the antitumor selectivity of $\beta$-hederin. Similarly, Gauthier et al have evaluated the lupane-type and oleanane-type saponins from a structureactivity-relationship perspective. ${ }^{24,33}$ Numerous human cell lines were tested, including lung carcinoma, and also normal skin fibroblasts. In the case of oleanane-type saponins, the oleanolic acid derivatives were by far the most active, while hederegenin saponins were not so active. A comparative evaluation of the two studies described here leads us to believe that an amide substitution at $\mathrm{C}-28$ could be a synthetic approach to convert nontoxic hederegenin saponins into more specifically toxic saponins. In general, these reports on the utilization of saponins and assessment of their structure-activity-relationship are interesting, but one of the problems associated with them is the randomized selection of the target cell line. This leads to ambiguity and, therefore, to generalization of the reported effect. Importantly, interpretation of the structure-activity-relationship becomes difficult when a saponin is not studied by different research groups in a similar target cell line.

It has also been unambiguously stated by many authors that the monodesmosidic saponins are in general hemolytic and more cytotoxic than the bisdesmosidic saponins. ${ }^{35}$ This is not based on evaluation of a large data set and, therefore, needs to be checked and, if required, corrected in a larger number of saponins. ${ }^{24}$ There are reports of certain monodesmosidic saponins being nonhemolytic and noncytotoxic, while contrasting cases have been reported in the case of bisdesmosidic saponins. The problem in the existing literature is the generalizations attempted by numerous authors. It would be critical and important that isolated saponins be individually tested for their structure-activity-relationship and correlation with cytotoxicity. A rapid screening in this regard would more or less provide a preliminary understanding of the mechanism. It is important to note the lack of adequate controls in studies performed on saponins in cell culture. Figure 3 gives a brief overview of the various mechanistic attributes that have been attributed to the saponins and the cellular compartments that they generally affect. While most saponins are reported to be effective in successful death of tumor cells, unless this is validated for normal and nontumor cell lines, the activity remains ambiguous. It is also important to establish the specific nature of the toxicity of saponins in target tumor cell lines by 

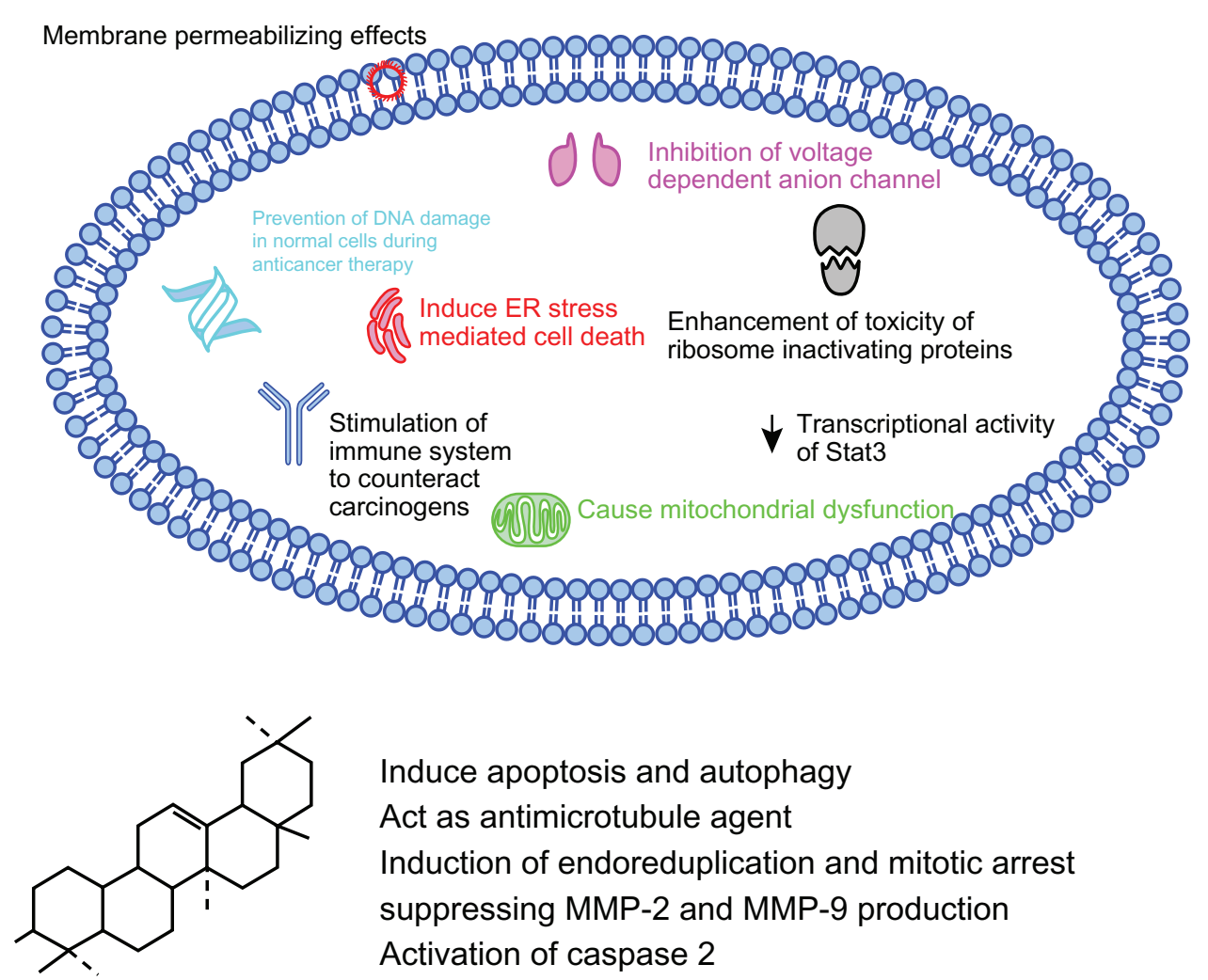

Induce apoptosis and autophagy

Act as antimicrotubule agent

Induction of endoreduplication and mitotic arrest

suppressing MMP-2 and MMP-9 production

Activation of caspase 2

Figure 3 A diagram showing the various cellular compartments affected by saponins in exhibiting their cytotoxic properties. In the figure above a saponin structure is followed by some general mechanism attributed to saponins in eliciting the antitumor effects.

a control experiment in nontarget cells. ${ }^{17}$ It is only after the specificity of the saponins is validated in target tumor cells, that the antitumor properties of saponins can be justified.

\section{Cytotoxic saponins in preclinical and clinical settings}

Clinical utilization of saponins as cytotoxic agents and their value in the treatment of tumors has not been extensively explored thus far. To reflect the potential applications of saponins as anticancer agents, herein we will consider some of the recent patents awarded for saponins as antitumor agents. $^{36}$

Some interesting work has been carried out at the preclinical level in validating the tumor-suppressive properties of saponins. In a study by Gutterman et al, the isolation and partial purification of novel triterpenoid saponins and two pure biologically active derivatives (termed avicins D and G) from Acacia victoriae, an Australian desert tree, were reported. The isolated compounds markedly inhibited growth of several tumor cell lines, with minimum growth inhibition in human foreskin fibroblasts, mouse fibroblasts, and immortalized breast epithelial cells at similar concentrations. The compounds induced cell cycle $\left(\mathrm{G}_{1}\right)$ arrest of the human
MDA-MB-453 breast cancer cell line and apoptosis of the Jurkat (T cell leukemia) and MDA-MB-435 (breast cancer) cell lines. There was a time-dependent partial inhibition of phosphatidylinositol-3-kinase activity in Jurkat $\mathrm{T}$ cells and phosphorylation in the downstream protein, Akt, whereas no effect was seen on the Ras/mitogen-activated protein kinase cascade. The authors also reported mitochondrial perturbation, chemoprevention, and inhibition of nuclear factor $\kappa \mathrm{B}$, concluding that triterpenoid saponins from $A$. victoriae have potential as novel anticancer agents. ${ }^{37-42}$ Furthermore, autophagy-induced cell death which could be regulated by treatment with chloroquine was also tested, and it was concluded that avicin D-induced autophagic cell death can be abrogated by knockdown of tuberous sclerosis complex 2 , which is a key mediator linking AMP-activated protein kinase, and mammalian target of rapamycin (mTOR). This validated autophagic cell death in the presence of avicins. ${ }^{43}$

Synthetic modifications of saponins have been successfully exploited for the treatment of many experimental tumors. The Sporn research group has been testing synthetically modified saponins in the treatment of different kinds of tumors. Some of the tumor models that have been tested include the treatment of estrogen receptor-negative 
mammary carcinogenesis by the synthetic triterpenoid, 2-cyano-3,12-dioxooleana-1,9(11)-dien-28-oic acid methyl ester (CDDO-Me) and the rexinoid, LG100268. These compounds were found to be useful as individual drugs for the treatment of tumors. ${ }^{44}$ In androgen-responsive and nonresponsive cancer cell lines (PC3 and DU145, respectively) CDDO-Me induced cell death at nanomolar and low micromolar concentrations. It was found to activate caspase-3, caspase-8, and caspase-9, and to induce poly(ADP-ribose) polymerase cleavage, internucleosomal DNA fragmentation, and loss of the 3-(4,5-dimethylthiazol-2-yl)-2,5-diphenyltetrazolium bromide reduction. ${ }^{45-47}$ There was also an increase in survival time for transgenic mice with experimentally induced pancreatic cancer. The effectiveness of CDDO-Me has also been validated in an experimental tumor model of lung cancer. ${ }^{48}$ All the aforementioned studies indicate a potential role of saponins in tumor therapy and prevention of tumor growth. Most importantly, they suggest the future possibility of gaining leads from natural sources and doing some synthetic modifications in the sugar side chain, thus improving the effectiveness of tumor inhibition.

A patent was awarded for utilization of terpenoid and steroid saponins from Quillaja saponaria Molina. The invention described therein encompassed the novel discovery of anticancer agents for clinical applications. It was found to be successful in a number of human cancer cells. Quill saponins were found to be effective, mainly through deconstruction of the cell membrane. Anticancer activity in ex vivo settings was also reported for the extract from the plant Androsace umbellate Merr. The triterpene saponins (saxifragifolin B and saxifragifolin D) isolated from the plant resulted in inhibition of cancer cell growth and also induction of apoptosis. Similar anticancer activity has also been patented for Xanthocera sorbifolia, which is designated as an anticancer biangeloyl saponin. ${ }^{49,50}$

\section{Tumor-suppressive effects of saponins}

While the individual use of saponins as antitumor agents has been under the scientific scanner for more than 40 years, no single clinically relevant saponin with sole status as a pharmaceutical agent has been approved by the US Food and Drug Administration. An interesting utilization of saponins, which was first reported by Hebestreit et al, was their ability to enhance the toxicity of certain ribosome-inactivating proteins synergistically at submicellar concentrations. ${ }^{51}$ The ability for target-cell specific enhancement was then illustrated for a targeted toxin consisting of the epidermal growth factor as the targeting moiety and the ribosome-inactivating protein, saporin, as the toxic moiety. A million-fold enhancement of toxin-mediated cell death was obtained by a saponin mixture from Gypsophila paniculata Linn. The specificity was demonstrated by very low enhancement in a cell line that did not express the target receptor. ${ }^{52,53}$

Studies in vivo in a mouse model were able to corroborate these data, and thus provided further evidence that the saponins can serve as an enhancer of targeted toxins in the treatment of tumors. Other chemotherapeutic agents have also been combined with saponins, which were considered to enhance membrane transportation. Because transportation of drugs to the tumor site is one of the major problems associated with tumor therapy, saponins have been extensively investigated to fill this void. Cisplatin has been used in combination with a number of saponins. The best combination was found to be with ginsenosides isolated from Achyranthes bidentata. ${ }^{54}$ Similar effects have also been observed for saponins isolated from Albizia adianthifolia, ${ }^{55,56}$ for which the reported effects have been found to be highly structure-dependent. This was illustrated for Muraltia heisteria, where only two of four isolated saponins exhibited toxicity-enhancing properties.

Interestingly, while on the one hand certain structurespecific effects of saponins from different plants result in toxicity enhancement, ginsenosides isolated from Panax notoginseng have been found to be valuable in preventing cisplatin-induced nephrotoxicity. ${ }^{57,58}$ A processed ginseng mixture known as sun ginseng, which has an increased amount of the ginsenosides unique to red ginseng, was tested. The ginsenosides, Rh4 and Rk3, significantly reduced cisplatin-induced nephrotoxicity in LLC-PK1 cells in a dose-dependent manner. This contrasting role played by certain distinct saponins having a structural variation should be validated for their structure-activity-relationship. It is also worth commenting that many such studies provide a basis for the observed effect, but thereafter there is a void concerning the utilization of these products. In this context, recent approaches to targeting the saponins by using nanoparticulate drug delivery systems could be worthwhile and are now discussed.

\section{Nanoparticulate saponins and their role in cytotoxicity}

Although use of the immunostimulating complex matrix formed from Quillaja saponins dates back to the 1990s in vaccine adjuvant technology, their applicability at the clinical level is still not confirmed. In a recent report of a 
nanoparticulate formulation for $Q$. saponaria Molina, the authors observed a variation in cytotoxicity and, interestingly, suggested the possibility of clinical utilization of this approach. Hu et al reported that the saponin fractions of $Q$. saponaria Molina have cytotoxic activity against cancer cells in vitro, but are too toxic to be useful in the clinic. ${ }^{59}$ Q. saponaria Molina was bound to cholesterol, leading to formation of nanoparticles and thus the cytotoxicity was reduced. Another interesting strategy of combining saponins bearing an acyl chain with those without an acyl chain has also been reported. While acyl chain particles were used as killing and growth-inhibiting particles, others without the acyl chain were used to formulate so-called blocking and balancing effect particles. In theory, these particles can enhance cytotoxicity on the one hand, and, on the other hand, another part of the particle can reduce the toxicity, thereby balancing the enhancement effects. There were ten cell lines evaluated in this study, ie, THP-1 (a human monoblast cell line), Jurkat (acute lymphoblastic leukemia), U937 and U937-Vcr (human histiocytic lymphoma cell lines), a RPMI 8226/S cell line (a human histiocytic lymphoma cell line and its sublines 8226/ Dox40 and 8226/LR-5), MV-4-11 (a human acute myelocytic leukemia cell line), and CCRF-CEM (an acute lymphoblastic leukemia cell line and its subline CEM/VM-1). In nine of the 10 tumor cell lines, acyl chain saponin nanoparticles showed growth inhibiting and cancer cell-killing activity, while the blocking and balancing effect particles were active only in one cell line. The authors made no molecular observations nor did they observe any analysis of receptor level expression to account for the observed effects, and chose the monoblastoid lymphoma cell line (U937) for analyzing the mode of action. Low concentrations of killing and growth-inhibiting particles $(0.5$ and $2 \mu \mathrm{g} / \mathrm{mL})$ induced an irreversible exit from cell cycle differentiation as measured by cytokine production, and eventually programmed cell death (apoptosis). There was a 30-fold higher sensitivity to the tumor cells compared with normal monocytes. Interestingly, they observed a blocking of the cytotoxic effect by the killing and growth-inhibiting particles in a concentrationdependent manner.

While the example cited above gives interesting information about the preparation of nanoparticles using saponins as a matrix, there have been other studies on the utilization of different matrices for the sustained delivery of saponins and their cytotoxic effects. In one such study, Rejinold et al reported use of chitosan nanoparticles loaded with saponins and their ability to fight cancer. The cytotoxicity of the nanoparticles was analyzed in L929, NIH-3T3, KB, and PC3 cells, with no toxicity seen for the unloaded particles in a concentration range of $0.1-1.0 \mathrm{mg} / \mathrm{mL}$, whereas the nanosaponin formulation showed enhanced toxicity in the PC3 and KB cell lines. Internalization of the nanosaponins in L929 and PC3 cells was confirmed by conjugation of the nanosaponins with rhodamine. ${ }^{60}$ The authors concluded that nanosaponins could be effective therapeutic agents for cancer.

In our opinion, these studies pave the way forward for utilization of saponins at safer and nontoxic concentrations to elicit a cytotoxic effect. One of the critical points of these two highlighted studies is their inability to show targeted specificity of the formulations when used for cancer cells. Further work on the safety aspect and on the probability of conjugating the saponin particles with ligands specific for receptors that are overexpressed on the tumor surface could be one of the ways forward for saponin therapeutics in the future.

\section{Efficacy of saponins and clinical potential}

The number of studies addressing the efficacy of saponins has increased dramatically in the last few years. The structural diversity of the saponins is reflected in their different pharmacological properties and concomitant efficacy in cellular systems. The biological activities of saponins range from the antibacterial, antileishmanial, antifungal, antimalarial, antiplasmodial, antiviral, to the antitumoral. ${ }^{61}$ Most of the studies dealing with the biological effects of saponins were performed in vitro. However, the therapeutic and therefore clinical potential of saponins has to be proven in in vivo models. Based on in vitro studies, it is therefore not justifiable to make judgments about the clinical potential of any particular saponin. Therefore, we now focus on the in vivo studies reporting efficacy for saponins in terms of their clinical potential.

Numerous steroidal and tritepenoidal saponins exhibit cytotoxic properties. It is thus not surprising that most of the in vivo studies investigated the antitumor efficacy of the different saponins. This is indeed one of the most promising applications of saponins. For instance, deltonin, a steroidal monodesmosidic saponin from Dioscorea zingiberensis Wright, hampered tumor growth in tumor-bearing BALB/c mice after oral administration. ${ }^{62}$ Similarly, timosaponin A-III, a steroidal saponin from Anemarrhena sphodeloides Bunge, slowed tumor growth in a xenograft tumor model in BALB/c-nu mice, ${ }^{63}$ and ginsenoside Rg3, from the American ginseng, Panax quinquefolius L, inhibited growth of human colon cancer cells in a xenograft tumor model. ${ }^{23}$ Suppressed tumor growth was also observed for other saponins like 
echinosid A from the sea cucumber Holothuria nobilis Selenka, ${ }^{64}$ ginsenosides Rk1 and Rk5, ${ }^{65}$ senegin III from Polygala senega $\mathrm{L},{ }^{66} \alpha$-hederin from Hedera helix $\mathrm{L},{ }^{67}$ escin from Aesculus wilsonii Rhed, ${ }^{68}$ Rhizoma paridis saponins from Paris polyphylla var yunnanensis $\mathrm{Fr},{ }^{69}$ saponins from G. paniculata L, ${ }^{51,52}$ and several other saponins. ${ }^{52,53,70-79}$

A further prominent feature of saponins is their antimicrobial activity. Diosgenyl 2-amino-2-deoxy-beta-D-glucopyranoside was medically active against Staphylococcus aureus and Enterococcus faecalis in a wound model simulating surgical site infections in BALB/c mice. ${ }^{80} \mathrm{~A}$ saponin fraction from the roots of Astragalus membranaceus Fisch with astragaloside IV was found to protect against microbial sepsis in mice from the Institute of Cancer Research.

Another important feature of some saponins is their ability to exert toxicity against different Leishmania spp, such as L. mexicana and L. major. Triterpenoid saponins (PX-6518) from Maesa balansae Mez showed high efficacy against cutaneous leishmaniasis in BALB/c mice. ${ }^{81}$ In addition to their prominent adjuvant properties, saponins from $Q$. saponaria Mol were shown to exert antiviral activity against the rhesus rotavirus in $\mathrm{BALB} / \mathrm{c}$ mice. ${ }^{82}$

In view of the high number of in vivo studies dealing with saponins as anticancer agents now at the forefront of research, it is obvious that the most promising clinical application of saponins could lie in the treatment of cancer. Inhibition of cell proliferation is essential for drug-induced cell death. Ideally, this is facilitated by induction of apoptotic processes, given that apoptosis is a controlled cellular deletion without inflammation. In contrast, necrosis is a degenerative process, which is accompanied by inflammation, rupture of the plasma membrane, and release of cytosolic compounds into the surrounding tissue. Saponins are generally regarded as membrane active-compounds that associate with cholesterol, causing rupture of the plasma membrane and concomitant release of cellular compounds. In general, this is a nonspecific process, which can be classified as saponin-induced necrosis. Due to the biological effects induced by necrosis, it is obvious that necrosis is always accompanied by a high degree of side effects.

From a therapeutic point of view, it is therefore desirable to use saponins that directly induce apoptotic processes or synergistically enhance the antitumor efficacy of other chemotherapeutic or anticancer agents. The clinical potential of any particular saponin is mainly determined by the mode of action by which it induces cell death. For example, echinoside A, a saponin from the sea cucumber $H$. nobilis Selenka, induced apoptosis and inhibited tumor growth in a nude mouse xenograft tumor model by specifically antagonizing the binding of topoisomerase $2 \alpha$ to DNA, which is based on a highly enzyme-specific interaction. Similar effects were observed for deltonin, ${ }^{62}$ alpha-tomatine, ${ }^{23}$ and tubeimoside- $1 .{ }^{83}$

In addition to these single treatments with saponins, there are several studies investigating the antitumoral efficacy of combinations of saponins, such as ginsenoside Rh2 or ginsenoside $\mathrm{Rg} 3$, with chemotherapeutic agents like paclitaxel. ${ }^{77,79}$ A further promising therapeutic approach is the combination of certain saponins from $G$. paniculata L. to augment the efficacy of targeted antitumor toxins, which are composed of a toxic enzyme and a binding domain that targets cancerassociated antigens. ${ }^{52,84}$ The underlying mechanism of this synergism is a saponin-mediated modulation of transport processes inside the cell, which facilitates efficient delivery of targeted toxins to their site of action. ${ }^{85}$

\section{Safety and tolerability}

Systematic in vivo studies of the overall safety and tolerability of individual saponin systems are relatively rare. For clinical applications of saponins as, eg, anticancer agents, it is obvious that the saponins should have high tolerance and not cause severe adverse effects. In general, saponins especially triterpene saponins, show acceptable tolerability in rodents and dogs. From our own experience of purified triterpene saponins from Saponaria officinalis L, we saw that a subcutaneous bolus injection of up to $5 \mathrm{mg} / \mathrm{kg}$ was tolerated by $\mathrm{BALB} / \mathrm{c}$ mice without causing harmful effects (unpublished observation). In a 90-day subchronic toxicity study in beagle dogs of the ginsenoside metabolite, protopanaxadiol, the NOAEL (no observed adverse effect level) was determined to be $6.7 \mathrm{mg} / \mathrm{kg} /$ day when given intravenously, which corresponds to high toxicological safety. ${ }^{86}$ Similar results were obtained for 20(S)-Ginsenoside Rg3, an effective antitumor agent. In beagle dogs, the NOAEL of $\mathrm{Rg} 3$ was considered to be $7.2 \mathrm{mg} / \mathrm{kg} /$ day via the intramuscular route. ${ }^{40}$

A preclinical toxicity assessment of the subchronic toxicity of a dammarane-type triterpenoid saponin with antitumor effect was assessed. Ginsenosides, which are one of the most prominently used saponins, were studied and reported by Liu et al. ${ }^{87}$ 20(S)-Ginsenoside $\mathrm{Rg} 3$ was given by repeated intramuscular administration to male and female Beagle dogs over a 26-week period at doses of 0, 0.70, 2.86 or $7.20 \mathrm{mg} / \mathrm{kg} /$ day (four dogs received each dose level). During the test period, as well as during the 8-week recovery period, clinical signs, mortality, body weight, food consumption, respiratory frequency, electrocardiogram, ophthalmoscopy, urinalysis, hematology, serum biochemistry, gross findings, 
organ weights, and histopathology were examined. In dogs treated with doses of 2.86 or $7.20 \mathrm{mg} / \mathrm{kg}$, hematological investigations revealed a dose-dependent increase in total white blood cell count and neutrophils, but a decrease in the percentage of lymphocytes. These effects were completely reversed during the recovery period, and no other adverse effects were observed. The NOAEL for both male and female dogs were considered to be $7.20 \mathrm{mg} / \mathrm{kg} /$ day.

This is one of the very few systematic preclinical assessments reported for saponins. It is important to note that the future success of saponins as cytotoxic or antitumor compounds needs to be carefully assessed by suitable preclinical screens. It is also important that proper controls are used, which should include normal human cell lines as an example. It is also obligatory to comprehend the fact that unless a better molecular understanding of the cellular uptake of saponins is characterized, the utilization of saponins as chemotherapeutic agents for cancer would hold lesser potential.

In a subchronic toxicity study of soybean saponins (Glycine $\max$ Merill), which exhibited growth-inhibitory effects on tumor cells, the LOAEL was determined to $707.2 \mathrm{mg} / \mathrm{kg} /$ day in male F344/DuCrj rats and $751.8 \mathrm{mg} / \mathrm{kg} /$ day in female rats after oral administration over 13 weeks. ${ }^{88}$ Although there are only a few studies evaluating the tolerance of saponins, it can be stated that most of the saponins appear to be safe, at least at therapeutic concentrations. However, there is a general lack of in vivo toxicological studies investigating the safety of saponins.

\section{Conclusion}

Based on the studies so far, it can be concluded that saponins hold a lot of therapeutic potential. It is not only their generalized detergent and cell permeability enhancing properties that are interesting, but also their direct application as cytotoxic and cytostatic agents. With the advancement of nanotechnology, it is surely apt to state that saponins in nanoparticulate form could show a lot of potential therapeutic applications. Synergistic application of saponins in targeted immune toxin therapy also appears to be a step for the future. It is important to mention that there are gaps in the toxicological information about many potential therapeutic saponins, which need to be filled by suitable in vivo assessments. It is also important to note that the specificity of antitumor properties must be carefully assessed, and effective doses should also be tested concomitantly in nontarget cell lines to validate specific antitumor effects. It is certainly worth mentioning that the potential of saponins as cytotoxic agents and their use in tumor therapy holds a lot of promise.

\section{Disclosure}

The authors report no conflicts of interest in this work.

\section{References}

1. Kensil CR. Saponins as vaccine adjuvants. Crit Rev Ther Drug Carrier Syst. 1996;13(1-2):1-55.

2. Melzig MF, Bader G, Loose R. Investigations of the mechanism of membrane activity of selected triterpenoid saponins. Planta Med. 2001; 67(1):43-48

3. Vincken JP, Heng L, de Groot A, Gruppen H. Saponins, classification and occurrence in the plant kingdom. Phytochemistry. 2007;68(3):275-297.

4. Hostettmann K, Marston A. Saponins. Vol 1. 1st ed. Cambridge: Cambridge University Press; 1995.

5. Zhou YY, Luo SH, Yi TS, et al. Secondary metabolites from Glycine soja and their growth inhibitory effect against Spodoptera litura. JAgric Food Chem. 2011;59(11):6004-6010.

6. Hill RA, Connolly JD. Triterpenoids. Nat Prod Rep. 2011;28(6): 1087-1117.

7. Zhao YM, Shi YP. Phytochemicals and biological activities of Dipsacus species. Chem Biodivers. 2011;8(3):414-430.

8. Voigt G, Hiller K. Advances in the chemistry and biology of the steroid saponins. Sci Pharm. 1987;55:201-222.

9. Woitke HD, Kayser JP, Hiller K. Advances in the research of triterpene saponins. A review. 2. Pharmazie. 1970;25(4):213-241.

10. Tschesche R. Biosynthesis of cardenolides, bufadienolides and steroid sapogenins. Proc R Soc Lond B Biol Sci. 1972;180(59):187-202.

11. Hiller K, Voigt G. New results in the research of triterpene saponins. Review. Pharmazie. 1977;32(7):365-394

12. Augustin M, Kuzina V, Andersen SB, Bak S. Molecular activities, biosynthesis and evolution of triterpenoid saponins. Phytochemistry. 2011;72(6):435-457.

13. Lacaille-Dubois MA, Wagner H. Bioactive saponins from plants: an update. In: Atta-ur-Rahman, Editor. Studies in Natural Products Chemistry, Bioactive Natural Products (Part B), Volume 21. Amsterdam, The Netherlands: Elsevier; 2000:633.

14. Sun HX, Xie Y, Ye YP. Advances in saponin-based adjuvants. Vaccine. 2009;27(12):1787-1796.

15. Setzer WN, Setzer MC. Plant-derived triterpenoids as potential antineoplastic agents. Mini Rev Med Chem. 2003;3(6):540-556.

16. Fuchs H, Bachran D, Panjideh H, et al. Saponins as tool for improved targeted tumor therapies. Curr Drug Targets. 2009;10(2):140-151.

17. Francis G, Kerem Z, Makkar HP, Becker K. The biological action of saponins in animal systems: a review. Br J Nutr. 2002;88(6):587-605.

18. Bachran C, Bachran S, Sutherland M, Bachran D, Fuchs H. Saponins in tumor therapy. Mini Rev Med Chem. 2008;8(6):575-584.

19. Sjolander A, Cox JC, Barr IG. ISCOMs: an adjuvant with multiple functions. J Leukoc Biol. 1998;64(6):713-723.

20. Bachran C, Heisler I, Bachran D, et al. Chimeric toxins inhibit growth of primary oral squamous cell carcinoma cells. Cancer Biol Ther. 2008;7(2):237-242.

21. Heisler I, Sutherland M, Bachran C, et al. Combined application of saponin and chimeric toxins drastically enhances the targeted cytotoxicity on tumor cells. J Control Release. 2005;106(1-2):123-137.

22. Podolak I, Galanty A, Sobolewska D. Saponins as cytotoxic agents: a review. Phytochem Rev. 2010;9(3):425-474.

23. Lee ST, Wong PF, Cheah SC, Mustafa MR. Alpha-tomatine induces apoptosis and inhibits nuclear factor-kappa B activation on human prostatic adenocarcinoma PC-3 cells. PLoS One. 2011;6(4):e18915.

24. Gauthier C, Legault J, Girard-Lalancette K, Mshvildadze V, Pichette A. Haemolytic activity, cytotoxicity and membrane cell permeabilization of semi-synthetic and natural lupane- and oleanane-type saponins. Bioorg Med Chem. 2009;17(5):2002-2008.

25. Guan F, Shan Y, Zhao X, et al. Apoptosis and membrane permeabilisation induced by macranthoside B on HL-60 cells. Nat Prod Res. 2011; 25(4):332-340. 
26. Podolak I, Janeczko Z, Galanty A, Michalik M, Trojanowska D. A triterpene saponin from Lysimachia thyrsiflora L. Acta Pol Pharm. 2007;64(1):39-43.

27. Siu FM, Ma DL, Cheung YW, et al. Proteomic and transcriptomic study on the action of a cytotoxic saponin (Polyphyllin D): induction of endoplasmic reticulum stress and mitochondria-mediated apoptotic pathways. Proteomics. 2008;8(15):3105-3117.

28. Song G, Guo S, Wang W, et al. Intestinal metabolite compound $\mathrm{K}$ of ginseng saponin potently attenuates metastatic growth of hepatocellular carcinoma by augmenting apoptosis via a Bid-mediated mitochondrial pathway. J Agric Food Chem. 2010;58(24):12753-12760.

29. Weng A, Bachran C, Fuchs H, Melzig MF. Soapwort saponins trigger clathrin-mediated endocytosis of saporin, a type I ribosome-inactivating protein. Chem Biol Interact. 2008;176(2-3):204-211.

30. Weng A, Melzig MF, Bachran C, Fuchs H. Enhancement of saporin toxicity against U937 cells by Gypsophila saponins. J Immunotoxicol. 2008;5(3):287-292.

31. Friess SL, Standaert FG, Whitcomb ER, Nigrelli RF, Chanley JD, Sobotka H. Some pharmacologic properties of holothurin A, a glycosidic mixture from the sea cucumber. Ann NY Acad Sci. 1960;90:893-901.

32. Gauthier C, Legault J, Piochon M, Lavoie S, Tremblay S, Pichette A. Synthesis, cytotoxicity, and haemolytic activity of chacotrioside lupanetype neosaponins and their germanicane-type rearrangement products. Bioorg Med Chem Lett. 2009;19(8):2310-2314.

33. Gauthier C, Legault J, Lavoie S, Rondeau S, Tremblay S, Pichette A. Synthesis and cytotoxicity of bidesmosidic betulin and betulinic acid saponins. J Nat Prod. 2009;72(1):72-81.

34. Liu Y, Lu WX, Yan MC, Yu Y, Ikejima T, Cheng MS. Synthesis and tumor cytotoxicity of novel amide derivatives of $\beta$-hederin. Molecules. 2010;15(11):7871-7883.

35. Acharya D, Mitaine-Offer AC, Kaushik N, et al. Cytotoxic spirostanetype saponins from the roots of Chlorophytum borivilianum. J Nat Prod. 2009;72(1):177-181.

36. Feng Y, Wang N, Zhu M, Feng Y, Li H, Tsao S. Recent progress on anticancer candidates in patents of herbal medicinal products. Recent Pat Food Nutr Agric. 2011;3(1):30-48.

37. Haridas V, Nishimura G, Xu ZX, et al. Avicin D: a protein reactive plant isoprenoid dephosphorylates Stat 3 by regulating both kinase and phosphatase activities. PLoS One. 2009;4(5):e5578.

38. Zhang C, Li B, Gaikwad AS, et al. Avicin D selectively induces apoptosis and downregulates p-STAT-3, bcl-2, and survivin in cutaneous T-cell lymphoma cells. J Invest Dermatol. 2008;128(11):2728-2735.

39. Gutterman JU, Lai HT, Yang P, Haridas V, Gaikwad A, Marcus S. Effects of the tumor inhibitory triterpenoid avicin $\mathrm{G}$ on cell integrity, cytokinesis, and protein ubiquitination in fission yeast. Proc Natl Acad Sci U S A. 2005;102(36):12771-12776.

40. Jayatilake GS, Freeberg DR, Liu Z, et al. Isolation and structures of avicins $\mathrm{D}$ and $\mathrm{G}$ : in vitro tumor-inhibitory saponins derived from Acacia victoriae. J Nat Prod. 2003;66(6):779-783.

41. Hanausek M, Ganesh P, Walaszek Z, Arntzen CJ, Slaga TJ, Gutterman JU. Avicins, a family of triterpenoid saponins from Acacia victoriae (Bentham), suppress H-ras mutations and aneuploidy in a murine skin carcinogenesis model. Proc Natl Acad Sci U SA. 2001;98(20):11551-11556.

42. Haridas V, Higuchi M, Jayatilake GS, et al. Avicins: triterpenoid saponins from Acacia victoriae (Bentham) induce apoptosis by mitochondrial perturbation. Proc Natl Acad Sci U SA. 2001;98(10):5821-5826.

43. Xu ZX, Liang J, Haridas V, et al. A plant triterpenoid, avicin D, induces autophagy by activation of AMP-activated protein kinase. Cell Death Differ. 2007;14(11):1948-1957.

44. Liby K, Risingsong R, Royce DB, et al. Prevention and treatment of experimental estrogen receptor-negative mammary carcinogenesis by the synthetic triterpenoid CDDO-methyl Ester and the rexinoid LG100268. Clin Cancer Res. 2008;14(14):4556-4563.

45. Dumont M, Wille E, Calingasan NY, et al. Triterpenoid CDDOmethylamide improves memory and decreases amyloid plaques in a transgenic mouse model of Alzheimer's disease. J Neurochem. 2009; 109(2):502-512.
46. To C, Kulkarni S, Pawson T, et al. The synthetic triterpenoid 2-cyano-3,12-dioxooleana-1,9-dien-28-oic acid-imidazolide alters transforming growth factor beta-dependent signaling and cell migration by affecting the cytoskeleton and the polarity complex. J Biol Chem. 2008;283(17):11700-11713.

47. Liby K, Royce DB, Williams CR, et al. The synthetic triterpenoids CDDO-methyl ester and CDDO-ethyl amide prevent lung cancer induced by vinyl carbamate in A/J mice. Cancer Res. 2007;67(6):2414-2419.

48. Liby K, Risingsong R, Royce DB, et al. Triterpenoids CDDO-methyl ester or CDDO-ethyl amide and rexinoids LG100268 or NRX194204 for prevention and treatment of lung cancer in mice. Cancer Prev Res (Phila). 2009;2(12):1050-1058.

49. Park JH, Kwak JH, Khoo JH, et al. Cytotoxic effects of triterpenoid saponins from Androsace umbellata against multidrug resistance (MDR) and non-MDR cells. Arch Pharm Res. 2010;33(8):1175-1180.

50. Zhang DM, Wang Y, Tang MK, et al. Saxifragifolin B from Androsace umbellata induced apoptosis on human hepatoma cells. Biochem Biophys Res Commun. 2007;362(3):759-765.

51. Hebestreit P, Weng A, Bachran C, Fuchs H, Melzig MF. Enhancement of cytotoxicity of lectins by Saponinum album. Toxicon. 2006;47(3): 330-335.

52. Bachran C, Durkop H, Sutherland M, et al. Inhibition of tumor growth by targeted toxins in mice is dramatically improved by saponinum album in a synergistic way. J Immunother. 2009;32(7):713-725.

53. Bachran D, Schneider S, Bachran C, et al. Epidermal growth factor receptor expression affects the efficacy of the combined application of saponin and a targeted toxin on human cervical carcinoma cells. Int $J$ Cancer. 2010;127(6):1453-1461.

54. Gaidi G, Correia M, Chauffert B, Beltramo JL, Wagner H, LacailleDubois MA. Saponins-mediated potentiation of cisplatin accumulation and cytotoxicity in human colon cancer cells. Planta Med. 2002;68(1):70-72.

55. Haddad M, Laurens V, Lacaille-Dubois MA. Induction of apoptosis in a leukemia cell line by triterpene saponins from Albizia adianthifolia. Bioorg Med Chem. 2004;12(17):4725-4734.

56. Haddad M, Miyamoto T, Laurens V, Lacaille-Dubois MA. Two new biologically active triterpenoidal saponins acylated with salicylic acid from Albizia adianthifolia. $J$ Nat Prod. 2003;66(3):372-377.

57. Baek SH, Piao XL, Lee UJ, Kim HY, Park JH. Reduction of Cisplatin-induced nephrotoxicity by ginsenosides isolated from processed ginseng in cultured renal tubular cells. Biol Pharm Bull. 2006;29(10):2051-2055.

58. Liu SJ, Zhou SW. Panax notoginseng saponins attenuated cisplatininduced nephrotoxicity. Acta Pharmacol Sin. 2000;21(3):257-260.

59. Hu K, Berenjian S, Larsson R, et al. Nanoparticulate Quillaja saponin induces apoptosis in human leukemia cell lines with a high therapeutic index. Int J Nanomedicine. 2010;5:51-62.

60. Rejinold N, Muthunarayanana M, Muthuchelianb K, Chennazhia KP, Nair SV, Jayakumar R. Saponin-loaded chitosan nanoparticles and their cytotoxicity to cancer cell lines in vitro. Carbohydr Polym. 2011;84(1): 407-416.

61. Dinda B, Debnath S, Mohanta BC, Harigaya Y. Naturally occurring triterpenoid saponins. Chem Biodivers. 2010;7(10):2327-2580.

62. Tong QY, Qing Y, Shu D, et al. Deltonin, a steroidal saponin, inhibits colon cancer cell growth in vitro and tumor growth in vivo via induction of apoptosis and antiangiogenesis. Cell Physiol Biochem. 2011;27(3-4):233-242.

63. Kang YJ, Chung HJ, Nam JW, et al. Cytotoxic and antineoplastic activity of timosaponin A-III for human colon cancer cells. J Nat Prod. 2011;74(4):701-706.

64. Liu J, Choudhuri S, Liu Y, Kreppel H, Andrews GK, Klaassen CD. Induction of metallothionein by alpha-hederin. Toxicol Appl Pharmacol. 1993;121(1):144-151.

65. Yoo JH, Kwon HC, Kim YJ, Park JH, Yang HO. KG-135, enriched with selected ginsenosides, inhibits the proliferation of human prostate cancer cells in culture and inhibits xenograft growth in athymic mice. Cancer Lett. 2010;289(1):99-110. 
66. Arai M, Hayashi A, Sobou M, et al. Anti-angiogenic effect of triterpenoidal saponins from Polygala senega. J Nat Med. 2011;65(1):149-156.

67. Feller G, Kugel A, Moonshine D, et al. African descents are more sensitive than European descents to the antitumor compounds alpha-hederin and kalopanaxsaponin I. Planta Med. 2010;76(16):1847-1851.

68. Zhou XY, Fu FH, Li Z, Dong QJ, He J, Wang CH. Escin, a natural mixture of triterpene saponins, exhibits antitumor activity against hepatocellular carcinoma. Planta Med. 2009;75(15):1580-1585.

69. Man S, Gao W, Zhang Y, et al. Antitumor and antimetastatic activities of Rhizoma Paridis saponins. Steroids. 2009;74(13-14):1051-1056.

70. Cai J, Zhu ZG, Yu CL, Lei LS, Wu SG. Saponin from Tupistra chinensis Baker inhibits mouse sarcoma S-180 cell proliferation in vitro and implanted solid tumor growth in mice. Nan Fang Yi Ke Da Xue Xue Bao. 2007;27(2):188-190, 194.

71. Wang J, Zhao XZ, Qi Q, et al. Macranthoside B, a hederagenin saponin extracted from Lonicera macranthoides and its anti-tumor activities in vitro and in vivo. Food Chem Toxicol. 2009;47(7):1716-1721.

72. Zhang T, Li Q, Li K, et al. Antitumor effects of saponin extract from Patrinia villosa (Thunb.) Juss on mice bearing U14 cervical cancer. Phytother Res. 2008;22(5):640-645.

73. Chae S, Kang KA, Chang WY, et al. Effect of compound K, a metabolite of ginseng saponin, combined with gamma-ray radiation in human lung cancer cells in vitro and in vivo. JAgric Food Chem. 2009;57(13): 5777-5782.

74. Gnoula C, Megalizzi V, De Neve N, et al. Balanitin-6 and -7: diosgenyl saponins isolated from Balanites aegyptiaca Del. display significant anti-tumor activity in vitro and in vivo. Int J Oncol. 2008;32(1):5-15.

75. Kang JH, Han IH, Sung MK, et al. Soybean saponin inhibits tumor cell metastasis by modulating expressions of MMP-2, MMP-9 and TIMP-2. Cancer Lett. 2008;261(1):84-92.

76. Einbond LS, Su T, Wu HA, et al. The growth inhibitory effect of actein on human breast cancer cells is associated with activation of stress response pathways. Int $J$ Cancer. 2007;121(9):2073-2083.

77. Xu TM, Xin Y, Cui MH, Jiang X, Gu LP. Inhibitory effect of ginsenoside $\mathrm{Rg} 3$ combined with cyclophosphamide on growth and angiogenesis of ovarian cancer. Chin Med J (Engl). 2007;120(7):584-588.

78. Tin MM, Cho CH, Chan K, James AE, Ko JK. Astragalus saponins induce growth inhibition and apoptosis in human colon cancer cells and tumor xenograft. Carcinogenesis. 2007;28(6):1347-1355.
79. Xie X, Eberding A, Madera C, et al. Rh2 synergistically enhances paclitaxel or mitoxantrone in prostate cancer models. J Urol. 2006; 175(5):1926-1931.

80. Cirioni O, Myszka H, Dawgul M, et al. In vitro activity and in vivo efficacy of the saponin HSM1 alone and in combination with daptomycin and vancomycin against gram-positive cocci. J Med Microbiol. 2011; 60(Pt 9):1337-1343.

81. Inocencio da Luz RA, Vermeersch $M$, Deschacht $M$, et al. In vitro and in vivo prophylactic and curative activity of the triterpene saponin PX-6518 against cutaneous Leishmania species. J Antimicrob Chemother. 2011;66(2):350-353.

82. Tam KI, Roner MR. Characterization of in vivo anti-rotavirus activities of saponin extracts from Quillaja saponaria Molina. Antiviral Res. 2011;90(3):231-241.

83. Zhang Y, Xu X, He P. Tubeimoside-1 inhibits proliferation and induces apoptosis by increasing the Bax to Bcl-2 ratio and decreasing COX-2 expression in lung cancer A549 cells. Mol Med Report. 2011;4(1):25-29.

84. Bachran C, Weng A, Bachran D, et al. The distribution of saponins in vivo affects their synergy with chimeric toxins against tumours expressing human epidermal growth factor receptors in mice. $\mathrm{Br} J$ Pharmacol. 2009;159(2):345-352.

85. Weng A, Bachran C, Fuchs H, Krause E, Stephanowitz H, Melzig MF. Enhancement of saporin cytotoxicity by Gypsophila saponins - more than stimulation of endocytosis. Chem Biol Interact. 2009;181(3): 424-429.

86. Gao YL, Liu ZF, Li CM, Shen JY, Yin HX, Li GS. Subchronic toxicity studies with ginsenoside compound $\mathrm{K}$ delivered to dogs via intravenous administration. Food Chem Toxicol. 2011;49(8):1857-1862.

87. Liu JP, Lu D, Nicholson RC, Li PY, Wang F. Toxicity of a novel antitumor agent 20(S)-ginsenoside Rg3: A 26-week intramuscular repeated administration study in Beagle dogs. Food Chem Toxicol. 2011;49(8): $1718-1727$

88. Cho YM, Imai T, Ito Y, et al. A 13-week subchronic toxicity study of dietary administered saponin-rich and isoflavones-containing soybean extract in F344 rats. Food Chem Toxicol. 2009;47(8):2150-2156.
Botanics: Targets and Therapy

\section{Publish your work in this journal}

Botanics: Targets and Therapy is an international, peer-reviewed, open access journal focusing on the discovery and development of active compounds based upon or found naturally occurring in the plant kingdom that may have therapeutic potential in any disease state. The manuscript management system is completely online and includes a very

Submit your manuscript here: http://www.dovepress.com/botanics-targets-and-therapy-journal

\section{Dovepress}

quick and fair peer-review system. Visit http://www.dovepress.com/ testimonials.php to read real quotes from published authors. 